\title{
Metachronous rectal metastasis from invasive ductal carcinoma of the male breast
}

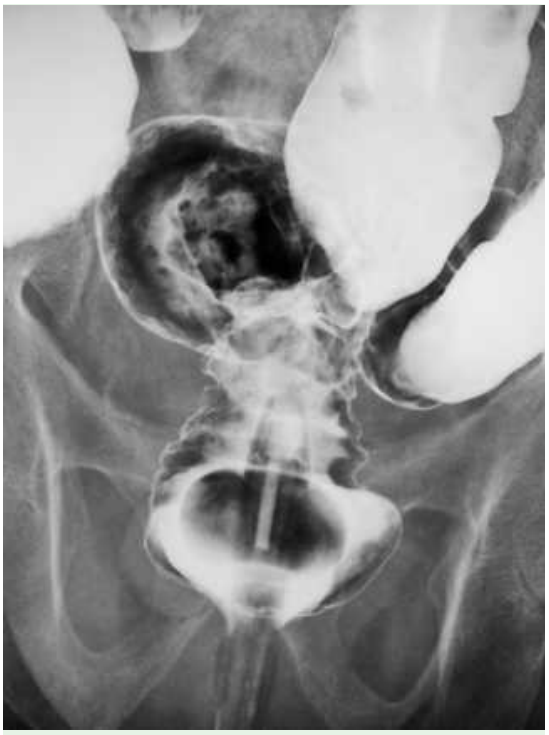

Fig. 1 Barium enema showed rectal stenosis.

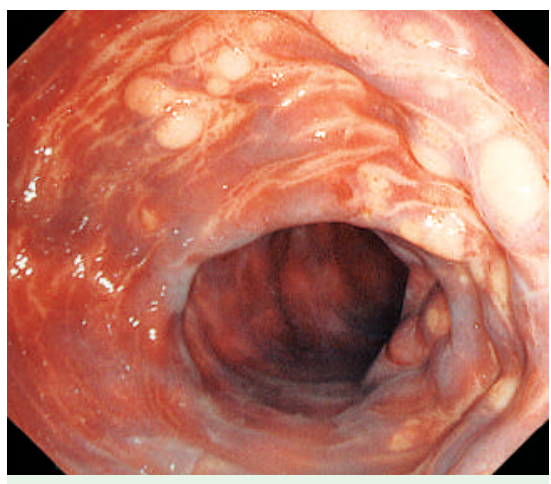

Fig. 3 Colonoscopy revealed edema and yellowish-white polypoid leasions in the rectal mucosa.

A 64-year-old man underwent left mastectomy for carcinoma of the breast at Teikyo University Hospital. Microscopic and immunohistochemical examination revealed estrogen-receptor-positive invasive ductal carcinoma without lymph node involvement. The patient received antiestrogen therapy for 6 months, and the clinical follow-up showed no signs of tumor recurrence. After a disease-free interval of 3 years, multiple liver metastases were detected, and antiestrogen therapy was resumed. Although the liver metastases decreased in size and there was no change in the patient's condition, he was admitted to our hospital after 4 years for anemia and blood in his stools. A bar-

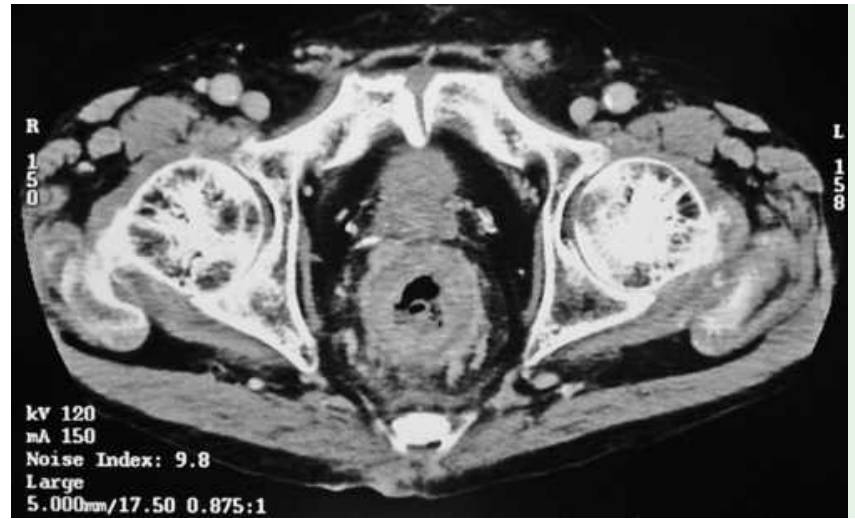

Fig. 2 Computed tomography demonstrated eccentric thickening of the wall of the rectum.

( $\bullet$ Fig. 1), and a computed tomography scan demonstrated eccentric thickening of the wall of the rectum ( $\bullet$ Fig. 2). Colonoscopy revealed edema and yellowishwhite polypoid lesions in the rectal mucosa ( Fig. 3). A rectal biopsy showed diffuse tissue infiltration by tumor cells (๑ Fig. 4). Immunohistochemical staining for estrogen receptor showed positive ( $\bullet$ Fig. 5). The pathologist classified the tumor as metastasis of invasive ductal carcinoma of the breast. The patient was treated with hormonal therapy. A barium enema carried out after hormonal therapy showed that the rectal stenosis had improved. At the present time, he is doing well as an outpatient and has not had any complaints.

Rectal metastasis of invasive ductal carcinoma is very rare $[1,2]$; second primary malignancies are more common than gastrointestinal tract metastases in patients with a history of breast cancer [3]. For this reason, we first diagnosed the rectal lesion as a type- 4 rectal cancer, because the mucosa of the rectum was edematous, granular, and gyriform-like in appearance. Immunohistochemical staining for estrogen receptor as well as the histological findings were also useful for establishing the diagnosis. Since patients with colorectal metastatic lesions of breast cancer have widespread metasta- 


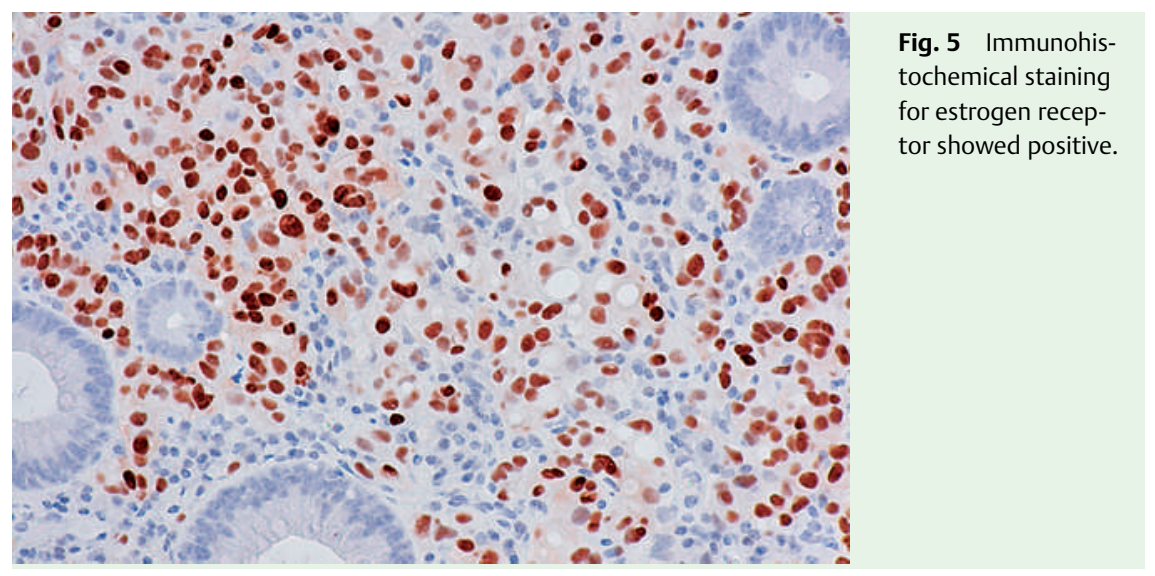

ses, systemic treatment with anticancer drugs and hormonal agents is recommended as first-line treatment.

\section{Endoscopy_UCTN_Code_CCL_1AD_2AC}

\section{Y. Ikeda, N. Morita, T. Ikeda}

Department of Surgery, Teikyo University School of Medicine, 2-11-1 Kaga, Itabashi-ku, Tokyo 173-8605, Japan

\section{References}

1 Yanagisawa K, Yamamoto M, Ueno E, Ohkouchi $N$. Synchronous rectal metastasis from invasive lobular carcinoma of the breast. J Gastroenterol Hepatol 2007; 22: 601 - 602

2 Cervi G, Vettoretto N, Vinco A et al. Rectal localization of metastatic lobular breast cancer: report of a case. Dis Colon Rectum 2001; 44: 453-455

3 Agarwal N, Ulahannan MJ, Mandile MA et al. Increased risk of colorectal cancer following 310 breast cancer. Ann Surg 1986; 203: $307-$
Bibliography

DOI $10.1055 / \mathrm{s}-2007-995392$

Endoscopy 2008; 40: E108-E109

(c) Georg Thieme Verlag KG Stuttgart · New York . ISSN 0013-726X

\section{Corresponding author}

\section{Y. Ikeda, MD}

Department of Surgery

Teikyo University School of Medicine

2-11-1 Kaga

Itabashi-ku

Tokyo 173-8605

Japan

Fax: +81-3-39622128

yikeda@med.teikyo-u.ac.jp 